\title{
O método como conteúdo: o ensino de história com fontes patrimoniais
}

Method as content: the teaching of history with sheets sources

\author{
Evandro Cardoso do Nascimento* \\ Universidade Federal do Paraná
}

Resumo Este artigo apresenta resultados de uma pesquisa realizada com alunos da $3^{\text {a }}$ série do ensino médio de um colégio de Matinhos/PR, em 2013. Partindo da concepção proposta por Zaragoza (1989) de que a inserção do método histórico como conteúdo é fator indispensável a uma aprendizagem histórica significativa, optou-se por utilizar fontes patrimoniais em sala de aula, objetivando o desenvolvimento da consciência histórica dos alunos (RÜSEN, 2001). A metodologia de ensino foi a Aula Oficina (BARCA, 2004), na qual o professor é caracterizado como o organizador das atividades problematizadoras e os alunos como agentes de sua própria formação. Os resultados acendem um método para a utilização de fontes primárias no ensino, em que o patrimônio é posto em evidência.

PALAVRAS-CHAVE: Educação histórica, Literacia histórica, Patrimônio histórico.

Abstract This article presents results of a survey of students of the 3rd year of high school a college of Matinhos/PR in 2013 Based on the concept proposed by Zaragoza (1989) that the inclusion of the historical method as content is essential factor to a historical learning significant, it was decided to use equity sources in the classroom aimed at the development of historical consciousness of the students (Rüsen, 2001). The teaching methodology was the Classroom Workshop (BARCA, 2004) in which the teacher is characterized as the organizer of the problemsolving activities and students agents of their own training. The results illuminate a method for using primary sources in teaching where the asset is put into evidence.

KEYWORDS: History education, Historical literacy, Heritage. 


\section{Introdução}

Este artigo apresenta uma pesquisa que teve como objetivo construir metodologias para ensinar História a partir de fontes primárias, incorporando o uso do patrimônio cultural local. Utilizar fontes primárias e pesquisas históricas em sala de aula não é uma ideia nova no Brasil, no entanto, pesquisas recentes, realizadas pelo Núcleo de Pesquisas em Publicações Didáticas da Universidade Federal do Paraná - NPPD/UFPR, revelam que, no cotidiano escolar, a maioria dos professores de História ainda ocultam dos seus alunos os métodos de pesquisa, apresentando a eles uma história pronta, construída e incontestável. Essa prática didática, segundo Zaragoza (1989), provoca um ocultamento da historicidade desta ciência e a História ensinada torna-se cada vez mais dogmática.

Ensinar métodos de pesquisa histórica aos alunos da educação básica significa muni-los das ferramentas necessárias às interpretações temporais. O conteúdo histórico, quando é ensinado ignorando seu processo de produção - sua historicidade, chega ao aluno como um conhecimento dogmático, essa transmissão impede a reflexão e a consciência histórica dos discentes torna-se limitada.

O historiador e professor britânico Peter Lee (2001) classifica o conhecimento histórico em duas categorias de análises, também chamadas de conceitos históricos: os conceitos substantivos, que são os conteúdos da história, isto é, são os temas e conceitos estudados pela disciplina; e os conceitos de segunda ordem, caracterizados pela natureza do pensamento histórico, isto é, são as formas de explicação, narrativa, interpretação e compreensão histórica. Possuir conhecimento histórico, neste sentido, não é apenas saber a História, mas simultaneamente saber como ela é construída, interpretada e narrada pelos sujeitos, ou seja, conhecer sua historicidade.

O ambiente da sala de aula, por muito tempo ocupado pelos professores de história e pelos alunos de história, agora, nesta perspectiva, é ocupado por pesquisadores. O professor-pesquisador, seguindo a proposta de Aula Oficina (BARCA, 2004), é o organizador e orientador das atividades a serem desenvolvidas, enquanto os alunos-pesquisadores, partindo de suas experiências na vida prática e da problemática proposta em conjunto com o professor, tornam-se agentes de sua aprendizagem. $\mathrm{O}$ passado deixa de ser algo pronto e transforma-se em um desafio para os pesquisadores, um escuro a ser esclarecido pela pesquisa, um memorial ao qual se fundamenta a identidade individual e coletiva dos sujeitos da aprendizagem.

Conhecer o passado é comunicar-se com ele, as fontes históricas são os meios para essa comunicação. As fontes revelam informações sobre o passado e as comunicam na medida em que são questionadas, lidas e interpretadas. "Sem fontes históricas não é possível fazer História. Sem fontes históricas também não é possível ensinar História" (PROENÇA, 1992, p. 126), quando as fontes são inseridas no processo de ensino e aprendizagem, as possibilidades de narrativas históricas ampliam e as origens dos discursos e ideologias são postas em questionamento.

Em algumas situações, as fontes históricas são utilizadas em sala de aula apenas para reforçar a narrativa do professor e do livro didático, neste caso não há uma 
inserção do método histórico para leitura destas fontes, há apenas uma preocupação científica para comprovação de um discurso. Utilizar fontes primárias sem inserir os métodos de pesquisa é semelhante a apresentar ao aluno a história pronta, construída e inquestionável, agora com mais um recurso que limita a interpretação do passado: a comprovação científica.

O patrimônio histórico é uma fonte, porém, se diferencia da tradicional noção de fonte enquanto documento histórico por estar inserido, de forma mais prática, no cotidiano das comunidades. O patrimônio é uma herança que tem o poder de evocar o passado (LE GOFF, 2003), ele tem a finalidade de fazer reviver o passado e promover uma relação temporal através da memória e dos valores atribuídos a ele (CHOAY, 2006). Nesta pesquisa, a opção em utilizar o patrimônio histórico como fonte de pesquisa, nas aulas, se justifica pela proximidade deste com a vida prática dos alunos.

A pesquisa empírica foi realizada no primeiro semestre de 2013, no município de Matinhos, localizado no Litoral do Paraná, com alunos das $3^{\mathrm{a}} \mathrm{s}$ séries do ensino médio do Colégio Estadual Sertãozinho. No primeiro momento, os alunos foram desafiados a escrever sobre a História local, o objetivo foi identificar seus conhecimentos tácitos; após explicar o projeto e esclarecer o conceito de patrimônio histórico, os alunos fizeram uma visita ao Centro Histórico de Paranaguá/PR (berço da colonização do Estado e distante $45 \mathrm{~km}$ de Matinhos), depois, em sala de aula, foi elaborado um inventário dos bens patrimoniais de Matinhos, para que os alunos escolhessem alguns deles para pesquisar, na sequência, os alunos foram a campo e, utilizando técnicas como questionários, entrevistas, visitas técnicas e pesquisas na internet, fizeram um levantamento histórico do local.

A metodologia utilizada, na análise da intervenção pedagógica, ampara-se em abordagens teóricas do âmbito da educação histórica, em que se considera uma aprendizagem histórica significativa àquela que desenvolve no aluno uma consciência histórica crítico-genética (RÜSEN, 2001; SCHIMIDT e CAINELLI, 2009). Os resultados apontam para um método de trabalho docente em que o patrimônio é utilizado como fonte primária e o método de pesquisa histórica passa a ser o conteúdo das aulas de História. Além de dinamizar as aulas, a metodologia em questão possibilita o reconhecimento e a valorização do patrimônio histórico local, fomentando as memórias e as identidades da comunidade matinhense.

\section{O patrimônio, as fontes e o método histórico}

Caracteriza-se patrimônio histórico os bens de natureza material, imaterial e natural detentores de referências às identidades e às memórias das diversas comunidades. O patrimônio material é o mais tradicional, em que se incluem os monumentos, objetos, obras e documentos de valor histórico; a noção de patrimônio imaterial é mais recente, nela se incluem os bens intangíveis, produto das manifestações mais populares como danças, lendas, receitas e celebrações; já o patrimônio natural, há quem diga que não é histórico devido ao fato de não expressar características culturais, porém, estudos mais recentes revelam que esse patrimônio é munido de aspectos culturais na medida 
em que, esses espaços, protagonizam relações complexas durante anos, a paisagem da praia, por exemplo, como defende o pesquisador Ferreira (2011), não pode ocorrer sem um diálogo entre o natural e o cultural.

Uma análise do conceito de patrimônio histórico também deve considerar a interdependência entre o material, o imaterial e o natural. No litoral do Paraná, por exemplo, as edificações mesclam-se com as paisagens da praia e da Serra do Mar, e as manifestações culturais se reproduzem nestes espaços, assim, tornam-se cada vez mais tênues os limites entre tais classificações. Pensar o patrimônio enquanto uma fonte histórica é extrair dele informações do passado, porém, diferente das fontes tradicionais, o patrimônio está vivo, em movimento, em constante reconstrução e seus significados históricos refletem o presente. A dimensão temporal que o patrimônio proporciona é espontânea, pois o passado não está registrado num livro, numa produção cinematográfica ou fechado num museu, este está inserido nas ruas, nas celebrações e nas paisagens, ou seja, na vida prática.

A historiografia tradicional, durante muito tempo, menosprezou os documentos ditos não oficiais, toda a história válida era produzida com base em documentos escritos e oficiais. Somente na revolução documental, da década de 1960 (LE GOFF, 2003; CHOAY, 2006), ampliou-se a noção de fonte histórica, quando as culturas materiais e imateriais passaram a ser objeto de investigação dos historiadores europeus. No Brasil, tal concepção foi adotada pelos historiadores somente no final do século XX, no processo de redemocratização política. Já a primeira década do século XXI foi marcada pela grande inserção de historiadores no campo do patrimônio, ampliando as possibilidades na reconstrução do passado histórico (NASCIMENTO, 2013).

O patrimônio é uma evidência histórica que acumula significados no tempo e no espaço, podendo ser encontrado em diferentes lugares, porém, uma leitura simplória deste pode desorientar a compreensão histórica. Para não correr esse risco, o método histórico deve ser aplicado na leitura e interpretação do patrimônio. A historiadora Bittencourt (2009, p. 328) faz um alerta ao uso equivocado das fontes históricas em sala de aula, segundo a autora, para os historiadores, as fontes históricas tem uma finalidade que não pode ser confundida com a situação da sala de aula. No ensino de História, o método histórico não será utilizado por historiadores, por isso, os critérios são diferentes, enquanto o historiador busca respostas científicas para produção de novos conhecimentos históricos, os alunos buscam respostas práticas e pessoais sobre a sua comunidade, para então obter novas compreensões históricas.

Para Zaragoza (1989), o método histórico deve ser utilizado em sala de aula obedecendo algumas etapas: $1^{\text {a }}$ ) conhecimento do atual discurso sobre o tema escolhido; $2^{a}$ ) problematização do tema a partir da vivência dos alunos; $3^{a}$ ) formulação de hipóteses; $4^{\mathrm{a}}$ ) análise das fontes; $5^{\mathrm{a}}$ ) interpretação do passado a partir das informações das fontes; e 6 $6^{\text {a }}$ formulação de resultados. Para Barca (2004), as etapas são: $1^{\text {a }}$ ) levantamento sistemático das ideias históricas dos alunos; $2^{\mathrm{a}}$ ) interpretação das fontes; $3^{\mathrm{a}}$ ) compreensão contextualizada; 4a) comunicação; e 5a) metacognição histórica. Tais propostas metodológicas se complementam e colocam o professor na condição de investigador social e organizador das atividades problematizadoras, enquanto os alunos como agentes de sua própria formação. 
Partindo das propostas de Zaragoza (1989) e Barca (2004), pensou-se, para esta pesquisa, um método estruturado em sete etapas: $1^{\mathrm{a}}$ ) apresentação do projeto; $2^{\mathrm{a}}$ ) elaboração de um inventário do patrimônio; $3^{\mathrm{a}}$ ) seleção dos bens patrimoniais; $4^{\mathrm{a}}$ ) produção de narrativas históricas a partir das ideias dos alunos sobre o patrimônio escolhido; $5^{\text {a) }}$ trabalho direto com as fontes patrimoniais utilizando imagens, entrevistas e documentos; $6^{\mathrm{a}}$ ) análise das informações das fontes; e $7^{\mathrm{a}}$ ) produção de narrativas históricas a partir das fontes. Este método contribui para uma educação patrimonial ao permitir a utilização de bens patrimoniais em sala de aula, e para educação histórica ao possibilitar o trabalho com fontes primárias.

Para a pesquisadora Pinto (2009, p. 275), o patrimônio histórico tomado como fonte nas aulas de história "permite o envolvimento dos alunos na construção do próprio saber, a partir dos seus interesses e motivações, desenvolvendo competências analíticas na abordagem das evidências patrimoniais". O resultado desta experiência é apresentado no próximo tópico deste artigo.

\section{Consciência histórica e patrimonial nas narrativas dos alunos}

Para o filósofo e historiador alemão Rüsen (2001), a consciência histórica é a capacidade individual do aluno para orientar-se intencionalmente no tempo, para o teórico são quatro os tipos de consciência histórica: tradicional, exemplar, crítica e genética. A consciência histórica tradicional caracteriza-se, unicamente, pela compreensão do passado a partir do presente, desconsiderando qualquer outra interpretação do passado; a consciência histórica exemplar busca, no passado, modelos de orientação em que se aceita passivamente o passado, aprendendo com os erros e acertos; a consciência histórica crítica é pautada na negação de uma única interpretação histórica; e a consciência histórica genética é pautada na aceitação e articulação dos diferentes pontos de vista históricos.

Para Schmidt (2009), a educação histórica objetiva a formação de uma consciência histórica crítico-genética, na qual a negação de uma única interpretação do passado serve como partida para a aceitação e articulação dos passados possíveis, algo que o método positivista acaba engessando, pois constrói apenas uma versão do passado e não reconhece o aluno enquanto sujeito histórico.

Pensar o patrimônio histórico, a partir dos elementos constitutivos da consciência histórica, permite caracterizá-lo como a materialização das experiências temporais, na qual as interpretações possíveis the atribuem significados que, por conseguinte, são orientadores da vida prática. Neste sentido, a consciência patrimonial almejada busca entender o patrimônio, não como gerador de uma única identidade, muitas vezes nacional, mas a pluralidade identitária dos diferentes grupos sociais envolvidos. Tal proposta tem por objetivo uma consciência patrimonial na qual o aluno "domine o uso do patrimônio e seu poder de identificação, utilizando-o como uma ferramenta para orientação no tempo" (NASCIMENTO, 2013, p. 134). 
Partindo dos conceitos até então apresentados, buscou-se investigar o desenvolvimento da consciência histórica e patrimonial nas narrativas escritas pelos alunos de Matinhos. Fazer com que a História tenha sentido para o aluno da educação básica é o desafio atual, a linha de pesquisa da educação histórica busca fazer isso, relacionando o conhecimento histórico à vida prática do aluno. A história local é um recurso que o professor pode utilizar para desenvolver essa aprendizagem, pois, nesta abordagem, há relações mais estreitas com o cotidiano do aluno e as fontes históricas primárias estão ao seu alcance.

Segundo Paim e Picolli (2007), as problemáticas locais foram inseridas no ensino da história com o objetivo de valorizar aquilo que é peculiar de cada local, contrapondo as generalizações da história global homogênea. Manique e Proença (1994) enfatizam que a história local constrói memórias e identidades em espaços mais limitados e exige menos abstração por parte dos alunos. Porém, o ensino da história local deve estar atrelado à história nacional e global, para que o aluno consiga fazer relações e desenvolver sua consciência histórica.

Paim e Picolli (2007) destacam que a história global e, principalmente, a história nacional enfatizam as semelhanças, por outro lado, a história local enfatiza as diferenças e peculiaridade. Em Matinhos, o patrimônio histórico local foi utilizado como fonte histórica pelos alunos, eles escreveram sobre a história local utilizando técnicas de pesquisas próprias da disciplina. O objetivo maior não foi ensinar a história oficial do local ou do município, através de seu patrimônio, mas fornecer aos alunos os meios e as técnicas para a produção deste conhecimento. Assim, o ensino da história passa a ser amparado pelo próprio método histórico, os alunos deixam de ter a história como um conhecimento estático e passam a perceber como ela é construída. O historiador e professor britânico Lee (2006) chama este método de literacia histórica.

No Colégio Estadual Sertãozinho, 54 alunos do ensino médio participaram da pesquisa. Num primeiro momento, as turmas das $3^{\circ}$ s séries $\mathrm{A}, \mathrm{B}$ e C foram desafiadas a produzirem a história local a partir das fontes patrimoniais existentes no município. Após explicar o projeto e esclarecer o conceito de patrimônio histórico - entendido aqui como uma construção cultural material, imaterial ou natural que sustenta a identidade histórica de um lugar ou de um povo -, os alunos passaram a entender o patrimônio enquanto uma fonte histórica, pois além de expressar beleza arquitetônica, turística e cultural, o patrimônio é uma representação do passado no presente, ele tem o poder de trazer o passado para mais próximo de todos.

Depois do trabalho em sala de aula, foi organizada uma visita técnica ao Centro Histórico de Paranaguá - tombado pelo Instituto do Patrimônio Histórico e Artístico Nacional IPHAN. A partir desta visita, os alunos perceberam a riqueza cultural e histórica do litoral e voltaram para Matinhos com o objetivo de explorar as riquezas históricas do local.

Em sala, foi solicitado aos alunos que separassem em grupos para pesquisa do patrimônio histórico material, imaterial ou natural. A turma foi dividida em três grupos, um para cada classificação patrimonial, cada grupo elaborou um inventário 
dos bens localizados em Matinhos, que poderiam ser listados independentes dos tombamentos ou registros oficiais.

Com o objetivo de realizar um levantamento dos conhecimentos prévios dos alunos sobre o patrimônio, foi solicitado que respondessem um questionário antes mesmo de começar a pesquisa, no questionário o aluno deveria escolher apenas 1 dos bens inventariados pela equipe e responder as seguintes perguntas: $\mathrm{O}$ patrimônio escolhido é de natureza material, imaterial ou natural? Por que você considera este patrimônio significativo (importante)? Qual a melhor maneira de preservá-lo? O que você sabe sobre a História deste patrimônio?

Os bens escolhidos foram:

- Material: Igreja de São Pedro, Casa no Balneário Flórida, Hospital Nossa Senhora dos Navegantes, Cinema das Sereias e Edifício Caiobá.

- Imaterial: Fandango, Saga da Caetana (lenda), Técnica da Pesca Artesanal, Vocabulário e Cultura Caiçara e Festa de São Pedro.

- Natural: Parque Rio da Onça, Praia Mansa, Pico de Matinhos, Morro do Boi, Morro do Escalvado e Ilha da Tartaruga.

Ao serem questionados sobre o motivo pelo qual consideram o bem patrimonial significativo, alguns alunos responderam o seguinte: Igreja de São Pedro: "porque é um dos poucos prédios antigos que ainda existem na cidade [...] a Igreja é a mais bonita, a arquitetura é antiga e as pinturas e vidros belíssimos." (L. O), "porque além de ser um patrimônio histórico é um lugar de visitação.” (J. F); Casa no Balneário Flórida: "porque apesar do passar dos anos ela ainda está intacta, além de ser considerada um patrimônio histórico." (J. B); Fandango: "porque é uma dança muito antiga e faz parte da cultura da região." (D. R); Pesca Artesanal: "pelo fato de morarmos na praia, há muito tempo a pesca é utilizada como meio de subsistência" (G. M); Vocabulário e Cultura Caiçara: "porque não podemos esquecer da origem de nossas famílias." (P. T); Saga da Caetana: "é uma das poucas lendas de Matinhos, por isso deve ser sempre lembrada como parte de nossa história." (C. S); Praia Mansa: "por ser um lugar bastante conhecido para nós, moradores, e por vários turistas também” (A. R); e Morro do Boi: "pela beleza natural e pela lenda que gira em torno desse local" (G. N).

Nas respostas dos alunos, há três preocupações evidentes: com o tempo, o belo e a memória. A primeira preocupação é escolher o patrimônio mais antigo, a segunda prende-se à beleza arquitetônica e cultural do patrimônio e a terceira preocupação é com relação ao aspecto da memória, isto é, quanto às lembranças que o patrimônio pode recuperar.

A pergunta mais importante, do ponto de vista do ensino da história, foi: $\mathrm{O}$ que você sabe sobre a história deste patrimônio? Como eles estavam sendo questionados, a partir de seus conhecimentos tácitos, a resposta era opcional e muitos alunos não responderam. Algumas respostam foram: Igreja São Pedro: "já foi a Catedral de Matinhos, foi por um tempo um pequeno Museu, e foi tombada como patrimônio histórico do município." (L. O); Casa do Balneário Flórida: "A casa é muito antiga, os 
tijolos são sem furo, as paredes grossas e a fachada é considerada patrimônio histórico." (J. B); Pesca Artesanal: "fui criada no meio da pesca, mas não tenho muito conhecimento [...] foi a forma para sobreviver." (R. S); Praia Mansa: "antes as praias eram tão bonitas [...] não tinha o calçadão, mas com o tempo foi se modificando." (F. M.); e Saga da Caetana: "a lenda conta um pouco de como era a cidade antigamente." (M. R.).

Após o levantamento dos saberes tácitos, os alunos montaram projetos de pesquisa para produzir conhecimentos históricos sobre os bens escolhidos. Através de questionários, entrevistas, visitas técnicas e pesquisas pela internet, arquivos da prefeitura e etc., os alunos buscaram mais informações e conhecimentos sobre o patrimônio e a história do local. O contato com as fontes históricas, as pesquisas de campo e, principalmente, as dificuldades na investigação, devido ao pouco material, levaram os alunos a compreenderem melhor o método histórico de investigação e também entender como o conhecimento histórico é produzido.

Depois da pesquisa de campo, os alunos receberam um segundo questionário, este com perguntas sobre o método utilizado em suas pesquisas e os conhecimentos históricos adquiridos. Dentre as respostas está a do aluno (J. B), ao ser questionado sobre o método utilizado na pesquisa da Casa do Balneário Flórida o aluno responde: "Foram realizadas perguntas ao proprietário do imóvel em questão, a respeito de sua conservação, curiosidades e construção". Ao ser questionado sobre a história do patrimônio pesquisado - a mesma pergunta do questionário dos conhecimentos tácitos, o aluno responde: "Foi construída a mais de 100 anos com alicerces de pedra que eram trazidos dos navios, as paredes são duplas e seus tijolos maciços, o concreto utilizado na época eram os Sambaquis. ${ }^{1}$ Sua fachada não pode ser alterada, pois é considerado um patrimônio histórico." Percebe-se, nas respostas do aluno, que algumas informações enriqueceram sua resposta, quando comparada à do primeiro questionário.

O proprietário da Casa do Balneário Flórida - pai do aluno (J. B) - desconhece sobre as origens do imóvel, a quem pertencia, quando foi construído e quais memórias são inerentes a ele. O próprio aluno, residente do imóvel, percebeu a falta de informações históricas do patrimônio, isso porque, quando o imóvel foi adquirido pela família, não houve interesse por sua memória. Outro aluno do mesmo grupo, o (E. $\mathrm{H}$ ) enfatizou o fato de o imóvel ser protegido por lei, proibindo o proprietário alterar sua estrutura.

A aluna (L. O), que escolheu a Igreja São Pedro, realizou uma pesquisa bibliográfica sobre o patrimônio, também fez alguns questionamentos com familiares, buscando informações que marcaram a história da igreja. Na pesquisa bibliográfica, a aluna descobriu que "A pequena Igreja de São Pedro, localizada no centro de Matinhos, é um dos poucos prédios históricos que sobraram. Construída entre 1938 e 1944, foi por muito tempo a matriz da cidade. Depois de ser substituída ficou desativada por um tempo e até abrigou um pequeno museu. Foi tombada como patrimônio histórico em 1987". Na pesquisa de campo, a aluna descobriu um fato recente que marcou a memória sobre a igreja: "Há uns 3 anos atrás, um homem que costumava ir rezar todos os dias na pequena igreja de São Pedro, teve um infarto e morreu perante o altar, marcando assim, mais uma história local". Percebe que o inusitado sempre permanece 
no imaginário popular. A aluna continua respondendo: "Quando paramos para olhar a igreja, podemos perceber que a calçada que cerca é diferente das demais, no chão há um cálice e uma hóstia representando a Santa Ceia”.

No Centro de Matinhos, há duas Igrejas cujo padroeiro é São Pedro, a menor e mais antiga, que foi pesquisada pela aluna, não recebe mais celebrações, foi restaurada e preservada como patrimônio por sua beleza arquitetônica e memória local.

Quanto ao patrimônio imaterial, três pesquisas se destacaram: A Saga da Caetana, o Fandango e o Vocabulário e Cultura Caiçara. A primeira foi pesquisada pela aluna (C. S), respondendo quanto ao método utilizado, ela escreve: "nosso grupo procurou conhecer a lenda pesquisando na internet, depois com uma pesquisa de campo entrevistando o Seu Francisco. Tiramos algumas fotos de um monumento sobre a Saga da Caetana”. A lenda é muito conhecida pelos moradores da região, o monumento, ao qual a aluna se refere, está localizado em Caiobá, trata-se de uma estátua que representa a onça e o cavalo - personagens da lenda. Quando questionada sobre a história do patrimônio, ela escreve: "é uma lenda que aconteceu em 1900 em Matinhos, conhecida até hoje, pois os antigos costumam passá-la de geração em geração." As memórias de Matinhos são colocadas na lenda de forma alegórica, expressam a identidade matinhense preservada nas famílias mais tradicionais. O aluno (F.R) relata que "dona Caetana passou essa história para familiares, e assim um foi passando para o outro".

Quanto ao Fandango, a aluna (D. R.) entrou em contato com a pesquisadora Daniele Tavares, da UFPR - Litoral, para realizar uma entrevista. A aluna relatou que, em Matinhos, o Fandango "não é apenas uma dança, e sim uma comemoração feita após a colheita da mandioca. Hoje as leis ambientais não permitem o plantio, portanto a dança não está sendo praticada como antes.” A aluna cita o Fandango da Ilha dos Valadares - Paranaguá - como uma referência deste patrimônio, porém, evidencia que a dança é praticada somente como diversão, isto é, sem o simbolismo de quando foi criada. Ela relata que a pesquisadora Daniele Tavares tem um primo e um parente, de 84 anos, que fabricam a Rabeca, ${ }^{2}$ segundo ela, este instrumento, bem como o tamanco masculino, é feito com a madeira de Caixeta. ${ }^{3}$

Pesquisando sobre o Vocabulário e a Cultura Caiçara, a aluna (D. R. R.) destaca que "a pesca, a festa de São Pedro, o Fandango e o palavreado 'meu caneco' fazem parte do dia a dia Caiçara, não é de hoje que esses costumes existem”, o aluno (P. $\mathrm{T})$ relata que "a cultura Caiçara vem desaparecendo ao longo dos anos [...] isso acontece porque a grande massa de pessoas que vem de fora trazem suas culturas." $\mathrm{O}$ grupo, que também teve a participação da aluna (J. S.), que pesquisou moradores antigos da região e percebeu que o "vocabulário se tonava nítido ao passo que fazíamos as entrevistas, expressões do tipo: meu caneco, vede e meu bom Jesus do Iguape são evidentes quando falamos com nativos Caiçaras de Matinhos." (J.S.).

No grupo que pesquisou o patrimônio natural, destacou-se a pesquisa do aluno (J. G), ele entrevistou um nativo da região, morador desde 1946, que presenciou toda a mudança estrutural do Pico de Matinhos, um pequeno morro de pedra próximo 
ao mar. Segundo o aluno, "com a pesquisa descobriu-se que o Pico era usado apenas como ponto observatório usado por bombeiros e guardas-vidas. Não existia escadaria e os moradores tinham que atravessar para Caiobá escalando as pedras, ou esperar a maré recuar para assim atravessar pela areia”. No primeiro questionário, este aluno havia relatado não conhecer sobre a história do Pico.

Sobre o Morro do Boi, uma aluna realizou uma pesquisa pela internet e relatou que o Morro do Boi "recebeu esse nome ainda no século XIX quando caçadores encontraram um boi perdido na região"(J. C.), porém, na pesquisa de campo, realizada pelo aluno (W. S.), que entrevistou um morador antigo da região, descobriu-se que o nome é dado "devido ao fato que os antigos diziam que o morro parecia um boi deitado", os alunos reconheceram que são necessárias mais pesquisas para se chegar a uma definição mais clara.

Os alunos (G. L.) e (G. S.) pesquisaram sobre a Ilha da Tartaruga, entrevistaram um pescador da região, ambos desconheciam a história da Ilha, porém, após a pesquisa relataram que "de acordo com o Vidal a Ilha da Tartaruga tem esse nome por seu formato, os moradores mais antigos achavam a ilha parecida com o casco de uma tartaruga" (G. S.).

Em suma, os alunos pesquisadores utilizaram métodos de investigação histórica. $\mathrm{O}$ objetivo foi produzir compreensões históricas sobre o patrimônio local relacionando, assim, a memória coletiva e a história local. O patrimônio histórico mostra-se como uma fonte primária eficaz na produção do conhecimento histórico, a proximidade dos alunos com os objetos pesquisados promove níveis maiores de empatia histórica.

Não foi possível ampliar as pesquisas com o patrimônio local, mas esta investigação revela a possibilidade de se ensinar história local a partir dos bens patrimoniais e trabalhar com fontes e métodos históricos. A disciplina de história é a que mais oculta seu método de investigação (ZARAGOZA, 1989), isso provoca um ensino dogmático e a ciência do passado perde sua historicidade na sala de aula. $\mathrm{O}$ método de pesquisa, utilizado como método de ensino, amplia a consciência histórica (RÜSEN, 2001) e a empatia (LEE, 2003). O professor deixa de ser o mediador do conhecimento para ser um organizador das atividades problematizadoras.

Uma análise quantitativa das narrativas revela que, dos 54 alunos que participaram do projeto, 32 não responderam a questão: "o que você sabe sobre a História deste patrimônio?” no primeiro questionário, porém, após a pesquisa realizada no âmbito do projeto, apenas 6 alunos não conseguiram responder a mesma pergunta no segundo questionário. 50 alunos realizaram pesquisa de campo com entrevistas a moradores locais, algumas destas entrevistas foram gravadas, transcritas e analisadas pelos alunos.

O projeto reuniu um acervo com imagens e documentos. Também foram realizadas algumas apresentações em sala de aula, com os resultados das pesquisas, alguns grupos apresentaram fotos das pesquisas de campo, oficinas de técnicas de 
fazer rede de pesca, música do fandango e etc. Em suma, o trabalho com o patrimônio envolveu os alunos e a comunidade na construção do conhecimento histórico local.

\section{Considerações finais}

Utilizar o patrimônio como um recurso didático para ensinar história local vai além da inserção de documentos históricos em sala de aula. O documento histórico por si é um recurso didático que multiplica a capacidade de interpretação histórica, o patrimônio, além disso, está vinculado à identidade histórica local dos agentes em aprendizagem. Portanto, utilizar o patrimônio histórico local, no processo de ensino e aprendizagem histórica, é colocar o aluno enquanto agente-construtor de seu conhecimento e identidade histórica.

O objetivo da pesquisa - construir metodologias para ensinar História a partir de fontes primárias - foi alcançado. Na abordagem patrimonial, a história global e o patrimônio tombado são reconhecidos pelos alunos como uma construção maior, com fins políticos, identitários e intelectuais, no qual o método histórico é utilizado com o intuito de resignificar o passado e seus usos. No âmbito do projeto, os alunos descobriram novas possibilidades para a história local, o conhecimento popular e os arquivos familiares foram incorporados nas investigações, fazendo com que a história tenha sentido prático. Isso possibilitou uma contribuição de duas vias: para os alunos, que estudaram os conteúdos de História a partir das suas experiências cotidianas; e para a comunidade, que participou do processo de construção do conhecimento, fornecendo dados e informações sobre o local. Isso valoriza os saberes locais e põe em evidência a memória dos diferentes atores sociais.

Entender o significado do passado, na vida presente, é um aspecto da consciência histórica, preservar a memória e a identidade deste passado é um aspecto da consciência patrimonial. Nas pesquisas, os alunos buscaram respostas para problemáticas do presente, utilizando o método de pesquisa histórica alcançaram algumas destas respostas. Tendo o patrimônio como ponto de partida para tal análise, este passa a ser reconhecido como um sustentáculo da memória e da identidade, a preservação é consequência deste reconhecimento.

\section{Referências}

BARCA, I. Aula Oficina: do Projeto à Avaliação. In. Para uma educação de qualidade: Atas da Quarta Jornada de Educação Histórica. Centro de Investigação em Educação (CIED) Instituto de Educação e Psicologia, Braga: Universidade do Minho. 2004.

BITENCOURT, C. M. F. Ensino de História: fundamentos e métodos. São Paulo: 3. ed. Cortez, 2009.

CHOAY, F. A alegoria do patrimônio. Tradução: Luciano Vieira Machado. São Paulo: 3. ed. Estação Liberdade: UNESP, 2006.

FERREIRA, F. N. Paisagens de Praia: o litoral como patrimônio (Rio Grande, XIX-XX). In. SCHIAVON, C. G. B. Anais eletrônicos do I Seminário de História e Patrimônio: diálogos e perspectivas. Rio Grande: EdiFURG, 2011. p. 549-569. 
LE GOFF, J. (1924). História e memória. [tradução: Bernardo Leitão, et al.] Campinas: 5. ed. Editora da Unicamp. 2003.

LEE, P. "Nós fabricamos carros e eles tinham que andar a pé": compreensão das pessoas do passado. In. BARCA, I. (Org.). Educação histórica e museus. Braga: CIED, Universidade do Minho. 2003.

LEE, P. Em direção a um conceito de literacia histórica. Educar, Curitiba: UFPR, p. 131-149, 2006.

LEE, P. Progressão da compreensão dos alunos em História. In: BARCA, Isabel (Org.). Perspectivas em Educação Histórica. Actas das Primeiras Jornadas Internacionais de Educação Histórica. Braga: Universidade do Minho, 2001. p. 13-29.

MANIQUE, A. P.; PROENÇA, M. C. Didáctica da história: patrimônio e história local. 1. Ed, Lisboa: Texto, 1994.

NASCIMENTO, E. C. Educação patrimonial: perspectivas da educação histórica. Ed. Do Autor, Matinhos: 2013.

PAIM, E. A.; PICOLLI, V. Ensinar história regional e local no ensino médio: experiências e desafios. História \& Ensino: Revista do Laboratório de Ensino de História. Londrina: Ed. UEL, p. 107-126, 1995.

PINTO, H. O triângulo patrimônio-museu-escola: que relações com a Educação Histórica? In. SCHMIDT, M. A. BARCA, I. Aprender História: perspectivas da educação histórica. Ijuí: Editora: Unijuí. 2009.

PROENÇA, M. C. Didácticas da História. Lisboa: Universidade Nova de Lisboa, 1992.

RÜSEN, J. Razão histórica: teoria da história: os fundamentos da ciência histórica. Tradução de Estevão de Rezende Martins, Brasília: Editora Universidade de Brasília, 2001.

SCHMIDT, M. A. M. dos Santos. Cognição histórica situada: que aprendizagem histórica é esta? In. SCHMIDT, M. A. BARCA, I. Aprender História: perspectivas da educação histórica. Ijuí: Unijuí. 2009

SCHMIDT, M. A. CAINELLI, M. Ensinar História. (Coleção Pensamento e ação na sala de aula) São Paulo: Scipione, 2009.

ZARAGOZA, G. La investigación y la formación del pensamiento histórico del adolescente. In. CARRETERO/M.; POZO, J. I.; ASENSIO, M. (compiladores). La enseñanza de las Ciencias Sociales. Madrid: Visor Distribuciones, 1989.

\section{Notas}

\footnotetext{
${ }^{1}$ Os Sambaquis são amontoados de conchas formados no litoral entre 6.500 a 1.500 anos atrás. Durante o período colonial era utilizado em construções.

${ }^{2}$ Instrumento musical utilizado no Fandango.

${ }^{3}$ A Caixeta (Tabebuia Cassinoides) é uma árvore típica do litoral, sua madeira macia facilita o trabalho artesanal.
} 
* Mestrando pela Universidade Federal do Paraná, Curitiba, Paraná, Brasil.

\section{Correspondência}

Evandro Cardoso do Nascimento - Centro de Ensino Instituto Educ. Rua Washington Luiz, 62, Jardim Eldorado. CEP: 83221060 - Paranaguá, Paraná, Brasil.

E-mail: evandrohistoria@hotmail.com

Recebido em 14 de agosto de 2014

Aprovado em 20 de outubro de 2014 
